\title{
PAPER
}

\section{Loss of spatial learning in a patient with topographical disorientation in new environments}

\author{
P Turriziani, G A Carlesimo, R Perri, F Tomaiuolo, C Caltagirone
}

\begin{tabular}{|c|c|}
\hline & J Neurol Neurosurg Psychiatry 2003;74:61-69 \\
\hline $\begin{array}{l}\text { See end of article for } \\
\text { authors' affiliations } \\
\ldots \ldots \ldots \ldots \ldots \ldots \ldots \ldots \\
\text { Correspondence to: } \\
\text { G A Carlesimo, IRCCS } \\
\text { Fondazione Santa Lucia, } \\
\text { Via Ardeatina 306, 00179 } \\
\text { Rome, Italy; } \\
\text { memolab@hsantalucia.it } \\
\text { Received } \\
7 \text { February } 2002 \\
\text { In revised form } 28 \text { June } \\
2002 \\
\text { Accepted } 19 \text { September } \\
2002\end{array}$ & $\begin{array}{l}\text { The case is described of a patient who, following cerebral hypoxia, developed severe difficulty in ori- } \\
\text { enting himself in new environments in the context of a mild global amnesic syndrome. Some episodes } \\
\text { he related suggested that his main difficulty was remembering the spatial/directional value of } \\
\text { landmarks he recognised. A neuroradiological examination documented severe bilateral atrophy of the } \\
\text { hippocampi associated with atrophic changes in the cerebral hemispheres, most marked in the dorsal } \\
\text { regions. Neuropsychological and experimental evaluation showed a severe deficit of spatial learning } \\
\text { with substantially preserved ability to learn verbal and visual-object information. He was also virtually } \\
\text { unable to learn a route in a maze task based exclusively on spatial data, but the availability of visual } \\
\text { cues substantially improved his learning. Finally, he performed within normal limits on various tests } \\
\text { investigating knowledge acquired premorbidly regarding famous buildings, routes in the town he had } \\
\text { been living in since childhood, and geography. Topographical disorientation may be subtended by a } \\
\text { specific difficulty in storing the spatial/directional value of visual landmarks in novel environments. The } \\
\text { hippocampus appears to be involved in the acquisition of new topographical spatial knowledge. }\end{array}$ \\
\hline
\end{tabular}

T opographical disorientation is a syndrome characterised by impaired ability to navigate in the real world. Cases of topographical disorientation are typically described in terms of perceptual or mnestic difficulties. ${ }^{1-5}$ In the perceptual type (topographical agnosia), visual processing of places, including landmarks, and space exploration are impaired, thus resulting in a deficient internal representation of the environment. In the mnestic type (topographical amnesia), visual and spatial characteristics of the environment are normally processed but the patients fail to recall topographical information for the purpose of orientation.

Aguirre and D'Esposito ${ }^{6}$ recently proposed a taxonomy of cases of topographical disorientation by distinguishing four categories of the syndrome.

The first, described as landmark agnosia, is characterised by the inability to use salient environmental features for orientation. ${ }^{578}$ Most commonly, this disorder is a consequence of damage to the part of the neural system specialised for landmark representation; this is located in the right ventral occipito-temporal cortex (fusiform, lingual, and parahippocampal gyri ${ }^{9-11}$ ).

The second, egocentric disorientation describes people who are unable to represent the location of objects with respect to self even though they are able to identify prominent environmental objects. ${ }^{12}{ }^{13}$ Lesions of the right posterior parietal cortex are generally responsible for this deficit.

Third, allocentric spatial representation can also be damaged selectively, so that people affected by heading disorientation are unable to remember the direction to go with respect to the external environment. The few cases so far described (perhaps the patients described by Takahashi et al ${ }^{14}$ and Cammalleri et al ${ }^{15}$ ) had lesions in the retrosplenial cortex (posterior cingulate).

The fourth category of topographical disorientation described by Aguirre and D'Esposito is anterograde disorientation. People who have preserved way-finding in environments known before the onset of their impairment, but who are unable to create new representations of surrounding information, are classified in this category. ${ }^{16-21}$ Interestingly, in the patients reported so far with clinical manifestations of anterograde disorientation the prevalent impairment is an inability to learn the visual aspect of new environments. The location of cerebral damage in these individuals is similar to (but does not overlap) that of patients with landmark agnosia. Aguirre and D'Esposito ${ }^{6}$ underlined the fact that although the lingual and fusiform gyri were most regularly damaged in the reported cases of landmark agnosia, ${ }^{22}{ }^{23}$ the right parahippocampus was most consistently lesioned in the patients with anterograde topographical disorientation. ${ }^{17}{ }^{19}$

The specific role of distinct cortical areas in the ventromesial surfaces of occipital and temporal lobes in topographical orientation is an issue of debate. In particular, although convergent evidence from neuropsychological and functional neuroimaging investigation in healthy humans supports the involvement of the fusiform, lingual, and parahippocampal gyri, ${ }^{9-11}$ the role of the hippocampus in topographical learning is controversial. The identification of "place cells" (neurones that fire preferentially for a specific position in the environment) in the hippocampus of rodents ${ }^{24}$ and of "spatial view cells" (tuned to respond to a view of space) in the hippocampus of monkeys, ${ }^{25}$ as well as the impairment of place learning following hippocampal lesions in the rat, ${ }^{26}{ }^{27}$ support the critical importance of the hippocampal function for topographical learning in animals. However, there is little evidence of a comparable role of the hippocampus in humans. The unilateral removal of the hippocampus for the relief of pharmacologically untreatable seizures does not cause relevant way-finding deficits. ${ }^{28}{ }^{29}$ On the other hand, the memory impairment in patients with bilateral damage to the hippocampal formation also involves topographical representations, but it lacks selectivity, involving virtually all kinds of information. ${ }^{30}$ Functional neuroimaging studies in healthy humans have also yielded divergent results on the involvement of the hippocampus in topographical orientation. Some studies, using encoding or retrieval navigational tasks, have reported activation in the hippocampus proper, ${ }^{10}{ }^{31-34}$ while others have not. ${ }^{11} 35$

In this paper, we report the case of a man who, as a result of cerebral hypoxia, showed a particularly severe anterograde topographical disorientation in the context of a mild global amnesic syndrome. Considering that his difficulties are confined to the learning of spatial relations between visually processed objects, our findings suggest that in this patient topographical disorientation is subtended by a specific 
difficulty in storing the spatial/directional value of visual landmarks in novel environments. Moreover, as his neuroimaging investigations showed severe bilateral hippocampal atrophy, the case of this patient is consistent with the hypothesis of involvement of the hippocampus in the acquisition of new topographical spatial knowledge.

\section{CASE REPORT}

The patient was a 41 year old right handed man, employed as a sailboat skipper, with 13 years of formal education when, in January 1998, he was admitted to a hospital in Rome in a comatose state as a result of a heroin overdose. The patient was referred to our laboratory in March 1998. At that time, he complained of moderate difficulty in remembering day to day events and information so that he frequently referred to his notes (mainly appointments and things to do) in a pocket diary. However, his main complaint was a severe impairment of finding his way in unfamiliar environments. At no time during the period of our observation (from March 1998 to May 1999) did the patient show any substantial modification of his difficulty in navigating in places that were unfamiliar to him before the accident. Some episodes he reported suggest that his prevalent difficulty was remembering the spatial/directional value of landmarks he effectively recognised. For example, once when he was leaving a friend's house, he could not tell which direction to go to find his car. First he went right and walked along the street but he was unable to remember anything. So he came back and suddenly recognised the buildings and landscape around him. Continuing to walk in the same direction, he recognised more buildings and places. Finally, he recognised a laundry and, close to it, his car. These orientation problems seemed to be limited to unfamiliar environments. In fact, he said he was well oriented in places he knew well and had no problem in moving through areas of town which were familiar to him before the onset of the disease.

The patient gave informed consent to his participation in this study, and the ethics committee of our institute approved the protocol of the experiment.

\section{Neuroradiological examination}

Magnetic resonance imaging (MRI) of the patient's brain, done in July 1998, showed very marked atrophy of the hippocampi bilaterally. There was also moderate cortical atrophy particularly involving the frontal lobe, the parietal lobe, and the dorsal aspect of the temporal lobe. The posterior and ventral areas of the brain appeared less involved. No focal brain lesion was detected (fig 1).

\section{Neuropsychological assessment}

The patient was assessed with a variety of standard neuropsychological tests. The results are reported in table 1 . The patient's scores were normal on tests assessing general intelligence, executive function, language, and visual-spatial perceptual abilities.

\section{Memory}

As shown in table 2, the patient scored in the normal range on tests of verbal, visual, and spatial short term memory and on a visual imagery task (the Brook's matrix task) which requires the subject to listen to a sequence of sentences describing the placing of consecutive numbers in consecutive squares of a $4 \times 4$ square matrix and to form a mental image of the matrix. This test has been used extensively for evaluating visualspatial imagery and spatial working memory in behavioral experiments with normal subjects. In the long term memory domain, his deficit was specific for spatial information. He performed poorly on episodic memory tests for spatial position or visual-perceptual material involving spatial relations (Rey's figure). Conversely, he scored normally on

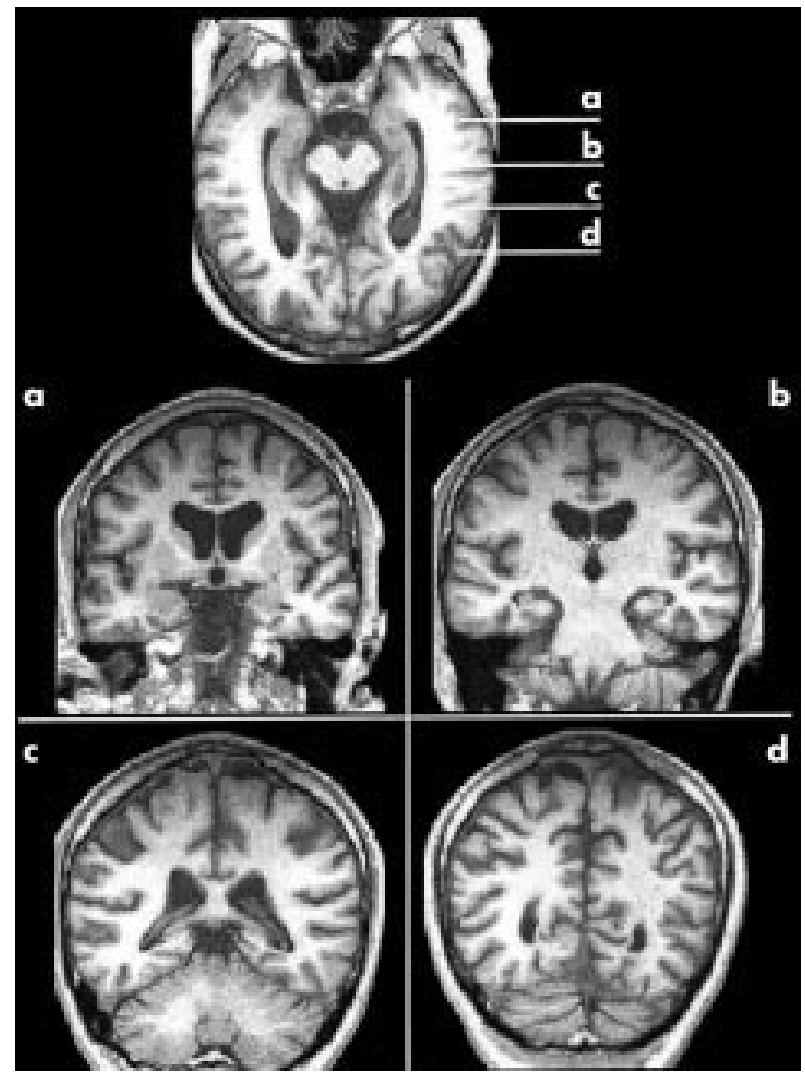

Figure 1 Axial and coronal slices of the patient's brain on magnetic resonance imaging.

memory tests for verbal material or visual stimuli in which spatial relations between constitutive elements were not critical (faces).

The results of the neuropsychological examination confirmed the clinical impression that this patient's topographical disorientation was caused by a memory deficit rather than an agnosic disorder. Indeed, he had normal visual-perceptual and visual-spatial working memory abilities and he was normally able to construct and manipulate new spatial layouts based on mental imagery. Moreover, the fact that he performed normally in the visual domain on memory tests involving visual-perceptual material but poorly on tests involving visual-spatial material suggests that his topographical disorientation was the result of an impairment of spatial learning. However, data supporting this latter claim are not compelling. His normal performance on the face recognition test could reflect sparing of the neural circuitry dedicated to processing physiognomic material, known to be distinct from that involved in memory for places. ${ }^{48}{ }^{49}$ Moreover, in Rey's figure reproduction, in which our patient obtained abnormal scores, memory for both visual details and spatial relations between constitutive elements is involved, so his deficient memory for visual-perceptual information could not be excluded on the basis of these data.

\section{EXPERIMENTAL INVESTIGATION}

The first goal of the experimental investigation was to confirm the patient's pattern of long term memory impairment disclosed by the neuropsychological analysis (that is, his deficit for spatial material being disproportionately more severe than that for verbal and visual-object material), by directly contrasting performance on memory tests for verbal, visualobject, and visual-spatial information. Second, we analysed the qualitative characteristics of the patient's route learning deficit using a theoretical model that distinguishes memory 
Table 1 Patient's performance on the neuropsychological battery of tests; references are also reported from which normative data, adjusted scores, and centile scores were derived

\begin{tabular}{|c|c|c|}
\hline Test & Patient & $\begin{array}{l}\text { Maximum possible } \\
\text { score }\end{array}$ \\
\hline \multicolumn{3}{|l|}{ General intelligence } \\
\hline \multicolumn{3}{|l|}{ Wechsler adult intelligence scale ${ }^{36}$} \\
\hline Verbal IQ & 121 & \\
\hline Performance IQ & 103 & \\
\hline Full scale IQ & 114 & \\
\hline Raven's coloured progressive matrices ${ }^{37}$ & 36 (=100\%ile) & 36 \\
\hline \multicolumn{3}{|l|}{ Language } \\
\hline Phrase construction ${ }^{38}$ & 25 (=100\%ile) & 25 \\
\hline Phonological word fluency ${ }^{38}$ & 36.5 (>50\%ile) & \\
\hline \multicolumn{3}{|l|}{ Executive functions } \\
\hline \multicolumn{3}{|l|}{ Modified card sorting test ${ }^{39}$} \\
\hline Criteria achieved & 6 (=100\%ile) & 6 \\
\hline Perseverative errors & 2.3 (>50\%ile) & 0 \\
\hline Non-perseverative errors & 7.3 (>50\%ile) & 0 \\
\hline \multicolumn{3}{|l|}{ Visual-perceptual abilities } \\
\hline \multicolumn{3}{|l|}{ Visual object and space perception battery 40} \\
\hline \multicolumn{3}{|l|}{ Object perception } \\
\hline Screening test & 20 (=100\%ile) & 20 \\
\hline Incomplete letters & 20 (=100\%ile) & 20 \\
\hline Silhovettes & 22 (>40\%ile) & 30 \\
\hline Object decision & 20 (=100\%ile) & 20 \\
\hline Progressive silhouettes & 12 (>80\%ile) & 20 \\
\hline \multicolumn{3}{|l|}{ Space perception } \\
\hline Dot counting & 10 (=100\%ile) & 10 \\
\hline Position discrimination & 20 (=100\%ile) & 20 \\
\hline Number locations & 10 (=100\%ile) & 10 \\
\hline Cube analysis & 9 (>30\% ile) & 10 \\
\hline Facial recognition ${ }^{41}$ & 48 (>70\%ile) & 54 \\
\hline Street's completion test ${ }^{42}$ & 9 (>50\%ile) & 14 \\
\hline Judgement of line orientation ${ }^{43}$ & 29 (>80\% ile) & 30 \\
\hline \multicolumn{3}{|l|}{ Copying drawing s ${ }^{38}$} \\
\hline Free copy & 12 (=100\%ile) & 12 \\
\hline With landmarks & 70 (=100\%ile) & 70 \\
\hline
\end{tabular}

for the visual aspects of landmarks from learning spatial information about the landmarks. ${ }^{12}$ Finally, we experimentally evaluated the patient's self report that his topographical disorientation was limited to learning routes in previously unfamiliar environments with substantial sparing of topographical knowledge acquired premorbidly.

On all experimental tasks, the patient's performance was compared with that of five normal male controls matched for education and age. In addition, two pathological controls were also examined to clarify whether the described pattern of memory impairment was specific to this patient or was a common sequel of cerebral damage; the first of these was a 32 year old amnesic patient with bilateral hippocampal atrophy following hypoxia; the other was a 75 year old patient with Alzheimer's disease and diffuse cortical atrophy.

\section{Experiment 1: comparison of verbal, visual, and spatial learning}

To verify the prevalent impairment of long term spatial memory, three tests were administered that directly contrasted the learning of two different types of material: verbal $v$ visual-object learning, verbal $v$ visual-spatial learning, and visual-object $v$ visual-spatial learning. To avoid problems of interpretation related to different absolute levels of performance in the patient and the age matched controls, each subject had first to achieve a minimum of $80 \%$ accuracy in learning one kind of material (for example, a word recognition test) and was then evaluated on the other learning test (for example, recognition of the spatial location of the word on a sheet of paper). On all three tests, if the subject did not reach the learning criterion ( $80 \%$ accuracy) on the first of the two tests on the first attempt, then study and testing phases were repeated until that criterion was achieved.

Tests

The memoranda of the verbal-visual recognition test are 20 coloured pictures of objects. In the study phase, each picture is presented to the patient for three seconds. When the learning criterion is achieved on the multiple choice verbal recognition test (discriminating the name of a previously seen object from two semantically related distractors), the visual-object test is administered. In each of 20 trials, three pictures depicting the same target object coloured with different hues of the same principal colour are presented, and the subject is requested to indicate the picture with the same colour as the one presented in the study phase.

The memoranda of the verbal-spatial recognition test are 20 nouns of concrete objects. During each of the 20 trials of the study phase, a word is presented in one of three different positions (left, middle, or right) on a horizontally placed sheet of A4 paper. When the learning criterion is reached on the verbal recognition test, the spatial test is administered. In each of the 20 trials, the patient is requested to indicate in which of the three positions (indicated by a cross on a sheet of paper) the word was placed during the study phase.

The memoranda of the visual-spatial recognition test are 20 black and white pictures of objects. During each study phase trial, a picture is presented in one of three different positions (left, middle, right) on a horizontally placed sheet of A4 paper. 


\begin{tabular}{|c|c|c|}
\hline Test & Patient & $\begin{array}{l}\text { Maximum score } \\
\text { possible }\end{array}$ \\
\hline Wechsler memory scale quotient ${ }^{44}$ & 103 & \\
\hline \multicolumn{3}{|l|}{ Verbal short term memory } \\
\hline Digit span forward ${ }^{45}$ & 7 (>50\%ile) & 9 \\
\hline \multicolumn{3}{|l|}{ Visual-spatial short term memory } \\
\hline Corsi block test forward ${ }^{45}$ & 6 (>50\%ile) & 9 \\
\hline Immediate visual memory ${ }^{38}$ & 22 (=100\%ile) & 22 \\
\hline \multicolumn{3}{|l|}{ Visual imagery } \\
\hline \multicolumn{3}{|l|}{ Brooks' matrix ${ }^{46}$} \\
\hline Longest correctly reproduced sequences & 8 (=100\%ile) & 8 \\
\hline Errors & 13 (>50\%ile) & 0 \\
\hline \multicolumn{3}{|l|}{ Verbal long term memory } \\
\hline \multicolumn{3}{|l|}{ Rey's 15 words learning task ${ }^{38}$} \\
\hline Immediate recall & 38.8 (>25\%ile) & 75 \\
\hline 15 min delayed recall & 6.1 (>10\%ile) & 15 \\
\hline \multicolumn{3}{|l|}{ Short story recall ${ }^{47}$} \\
\hline Immediate recall & 4.3 (>10\%ile) & 8 \\
\hline $20 \mathrm{~min}$ delayed recall & 3.5 (>5\%ile) & 8 \\
\hline \multicolumn{3}{|l|}{ Visual-object long ferm memory } \\
\hline Recognition memory of faces ${ }^{48}$ & 26 (>50\%ile) & 30 \\
\hline \multicolumn{3}{|l|}{ Visuo-spatial long term memory } \\
\hline \multicolumn{3}{|l|}{ Rey's figure $A^{47}$} \\
\hline Immediate reproduction & 5.5 (<5\%ile) & 36 \\
\hline 20 min delayed reproduction & 5.5 (<5\%ile) & 36 \\
\hline Supraspan spatial learning ${ }^{42}$ & 0 (<5\%ile) & $30.78 *$ \\
\hline
\end{tabular}

When the learning criterion is reached on the visual recognition test (by choosing the perspective of the object in the study phase out of three different perspectives of the same object), the spatial memory test is given. On this test the patient is requested to indicate in which of the three positions (indicated by a cross on a sheet of paper) the picture was placed during the study phase.

\section{Results and comment}

The performance scores of the patient and the controls on the tests of experiment 1 are given in table 3. Confirming his overall difficulty in learning new information, the patient needed three and four presentations of the stimulus material to reach the learning criterion on the verbal-spatial and visual-spatial recognition tests, respectively. However, these data also confirm the impression that his memory deficit for spatial information was disproportionately more severe than his memory deficit for verbal and visual data. On the verbal-visual test, after reaching the learning criterion on the verbal test, he also performed at the same level as normal controls on the visual test. In contrast, on the verbal-spatial and visual-spatial recognition tests, even after reaching the learning criterion on the verbal and visual recognition tests, he still performed at chance level on the spatial tests. These findings indicate also that when the patient correctly recognised the names or visual features of objects, he was still severely impaired in remembering their locations in space. Both the pathological controls differed from our patient in that they had a more homogeneous pattern of memory impairment. They obtained scores below the normal limits not only on the verbal-spatial and visual-spatial tests but also on the verbal-visual test.
Experiment 2: learning of visual, topological, metrical, and vectorial information

It is commonly agreed that route learning involves the acquisition of two main pieces of information about the environment: the identification and representation of salient environmental features (visual landmarks) and the structuring of a sequential representation of the spatial relations among landmarks, including topological, metrical, and vectorial characteristics. In this experiment, we contrasted the patient's ability to recognise visual objects and to memorise spatial relations between objects by evaluating his memory for topological, metrical, and vectorial information separately. As in experiment 1 , in order to control the patient's more general memory impairment, he was required to reach the learning criterion for the identity stimuli ( $80 \%$ accuracy) before the administration of visual or spatial tests.

Tests

Recognition memory for visual objects

The memoranda consist of 18 coloured photographs of buildings, cars, monuments, and home tools. During the study phase, the pictures are presented to the patient for three seconds each. When the learning criterion is reached on the verbal test (a multiple choice recognition test discriminating the object seen previously from two semantically related distractors), the visual test is administered. Three photographs, each reporting an exemplar of the same principal object (for example, three cars), are visually presented and the patient is required to indicate the one previously seen in the study phase.

Recognition memory for spatial relations

The aim of the reciprocal position learning test is to assess memory for object location specified by topological information. In this 
Table 3 Performance scores of the patient and of the healthy and pathological controls on tests in experiment 1 ; the number of trials needed to reach the learning criterion of $80 \%$ accuracy in the first testing phase of each test is given in parentheses

\begin{tabular}{|c|c|c|c|c|}
\hline & \multirow[b]{2}{*}{ Patient } & \multirow[b]{2}{*}{$\begin{array}{l}\text { Normal controls } \\
\text { (range) }\end{array}$} & \multicolumn{2}{|c|}{ Pathological controls } \\
\hline & & & $\begin{array}{l}\text { Patient with } \\
\text { hippocampal } \\
\text { atrophy }\end{array}$ & $\begin{array}{l}\text { Patient with } \\
\text { cortical atrophy }\end{array}$ \\
\hline \multicolumn{5}{|c|}{ Verbal-visual recognition test } \\
\hline Verbal & $19 / 20(1)$ & $18-20 / 20(1)$ & $18 / 20(1)$ & $18 / 20(3)$ \\
\hline Visual & $13 / 20$ & $12-16 / 20$ & $9 / 20 *$ & $8 / 20$ * \\
\hline \multicolumn{5}{|c|}{ Verbal-spatial recognition test } \\
\hline Verbal & $18 / 20(3)$ & $17-20 / 20(1)$ & $18 / 20(1)$ & $18 / 20(4)$ \\
\hline Spatial & $3 / 20 *$ & $10-16 / 20$ & $9 / 20 *$ & $2 / 20 *$ \\
\hline \multicolumn{5}{|c|}{ Visual-spatial recognition test } \\
\hline Visual & $17 / 20(4)$ & $17-20 / 20(1)$ & $18 / 20(1)$ & $18 / 20(5)$ \\
\hline Spatial & $5 / 20 *$ & $11-17 / 20$ & $5 / 20^{*}$ & $4 / 20^{*}$ \\
\hline
\end{tabular}

test, the memoranda are 40 black and white drawings of concrete objects taken from Snodgrass and Vanderwart's set. ${ }^{50}$ During each of the 20 trials of the study phase, a pair of semantically unrelated stimuli is presented visually for three seconds; the two items of the pair are reciprocally located on the page in four standard arrangements (right-left, left-right, top-bottom, bottom-top). When the learning criterion is reached on the visual test (discriminating the object that was paired with the stimulus target during the study phase from three semantically related alternatives), the spatial test is given. On each trial the subject is required to indicate which reciprocal position the two objects of a pair were located in during the study phase.

The proximity judgement test evaluates the ability to learn metrical information regarding the spatial relations between two objects. The memoranda are 100 black and white pictures from Snodgrass and Vanderwart's set. ${ }^{50}$ During each of 20 trials in the study phase, the drawings of three semantically unrelated objects are presented for three seconds. The reciprocal position of the pictures on the page is such that two objects of the triplet are closer to each other than to the third one. When the learning criterion is reached on the visual test (given two objects, the subject is requested to indicate which, among three semantically related alternatives, was the third object in the triplet), the spatial test is given. On each trial, a previously studied triplet is presented and the patient is asked which objects were closer together in the study phase.

The vector judgement test was administered to investigate spatial memory based on vector information. During the study phase, 20 black and white drawings of concrete objects randomly located on a sheet of A3 paper are simultaneously presented to the patient for 60 seconds. When the learning criterion is reached, the spatial test is administered. On each of the 20 trials, the patient is asked to indicate verbally in which direction of eight alternatives (north, northeast, east, southeast, and so on) he has to go to move from one object to another (for example, "in which direction do you go from the cow to the watering can?").

\section{Results and comment}

The performance scores on the tests in experiment 2 for the patient and the controls are shown in table 4 . In these tests also, the pathological controls performed below the normal controls in all cases. With the exception of the proximity judgement test (in which two presentations of stimulus material were needed), the patient reached the $80 \%$ accuracy

Table 4 Performance scores of the patient and of the healthy and pathological controls on tests in experiment 2; the number of trials needed to reach the learning criterion of $80 \%$ accuracy in the first testing phase of each test is given in parentheses

\begin{tabular}{|c|c|c|c|c|}
\hline & \multirow[b]{2}{*}{ Patient } & \multirow[b]{2}{*}{$\begin{array}{l}\text { Normal } \\
\text { controls } \\
\text { (range) }\end{array}$} & \multicolumn{2}{|c|}{ Pathological controls } \\
\hline & & & $\begin{array}{l}\text { Patient with } \\
\text { hippocampal } \\
\text { atrophy }\end{array}$ & $\begin{array}{l}\text { Patient with } \\
\text { cortical atrophy }\end{array}$ \\
\hline \multicolumn{5}{|c|}{ Recognition memory for visual objects } \\
\hline Verbal & $16 / 18(1)$ & $16-18 / 18(1)$ & $16 / 18(2)$ & $16 / 18(4)$ \\
\hline Visual & $18 / 18$ & $16-18 / 18$ & $15 / 18^{*}$ & $10 / 18^{*}$ \\
\hline \multirow{2}{*}{\multicolumn{5}{|c|}{ Spatial relationship learning }} \\
\hline & \multicolumn{4}{|c|}{ Reciprocal position learning test } \\
\hline Verbal & $19 / 20(1)$ & $19-20 / 20(1)$ & $18 / 20(1)$ & $18 / 20(4)$ \\
\hline Spatial & $4 / 20 *$ & $10-19 / 20$ & $8 / 20 *$ & $3 / 20 *$ \\
\hline \multicolumn{5}{|c|}{ Proximity judgement test } \\
\hline Verbal & $18 / 20(2)$ & $18-20 / 20(1)$ & $18 / 20(2)$ & $18 / 20(6)$ \\
\hline Spatial & $10 / 20^{*}$ & $14-18 / 20$ & $11 / 20^{*}$ & $9 / 20^{*}$ \\
\hline \multicolumn{5}{|c|}{ Vector judgements test } \\
\hline Verbal & $20 / 20(1)$ & $20 / 20(1)$ & $18 / 20(2)$ & $18 / 20(3)$ \\
\hline Spatial & $3 / 20 *$ & $5-9 / 20$ & $4 / 20 *$ & $3 / 20 *$ \\
\hline
\end{tabular}


Table 5 Performance scores of the patient and of the healthy and pathological controls on the maze learning task

\begin{tabular}{|c|c|c|c|c|c|c|c|c|}
\hline & \multirow{2}{*}{\multicolumn{2}{|c|}{ Patient }} & \multirow{2}{*}{\multicolumn{2}{|c|}{ Normal controls (range) }} & \multicolumn{4}{|c|}{ Pathological controls } \\
\hline & & & & & \multicolumn{2}{|c|}{$\begin{array}{l}\text { Patient with hippocampal } \\
\text { atrophy }\end{array}$} & \multicolumn{2}{|c|}{ Patient with cortical atrophy } \\
\hline & Trial & $\begin{array}{l}15 \mathrm{~min} \\
\text { delayed trial }\end{array}$ & Trial & $\begin{array}{l}15 \mathrm{~min} \\
\text { delayed trial }\end{array}$ & Trial & $\begin{array}{l}15 \text { min delayed } \\
\text { trial }\end{array}$ & Trial & $\begin{array}{l}15 \mathrm{~min} \text { delayed } \\
\text { trial }\end{array}$ \\
\hline $\begin{array}{l}\text { Without landmarks } \\
\text { condition }\end{array}$ & $43^{*}$ & $6 / 12$ & $10-17$ & $12 / 12$ & $21^{*}$ & $0 / 12$ & $32^{*}$ & $3 / 12$ \\
\hline $\begin{array}{l}\text { Few landmarks } \\
\text { condition }\end{array}$ & 16 & $4 / 12$ & $12-17$ & $12 / 12$ & $19^{*}$ & $5 / 12$ & $22^{*}$ & $0 / 12$ \\
\hline $\begin{array}{l}\text { Full landmarks } \\
\text { condition }\end{array}$ & 12 & $10 / 12$ & $11-15$ & $12 / 12$ & $25^{*}$ & $2 / 12$ & $23^{*}$ & $0 / 12$ \\
\hline
\end{tabular}

*Task interrupted because the patient appeared to be excessively frustrated by repeated failures. On the 43 th trial, he correctly reproduced the first seven blocks of the route.

learning criterion for stimulus identity on all other tests after only one study phase. This showed the substantial sparing of his memory when he could rely on a verbal or a visual strategy of stimulus learning. Another indication of the substantial sparing of his visual memory is that he scored within normal limits on the test for recognition memory for visual objects. In contrast, he performed at chance level or clearly below normal on all other tests investigating memory for spatial relations between objects (reciprocal position learning, proximity judgement, and vector judgement tests), suggesting that he was unable to permanently acquire any kind of information referring to space. The pathological controls did not show any dissociation between memory tests based on stimulus material. They performed poorly on all tests, regardless of the visual or spatial nature of the memoranda.

\section{Experiment 3: maze learning}

The behavioural, neuropsychological, and experimental evidence so far reported strongly suggests that the patient has lost the ability to permanently acquire memory for the spatial components of topographical environments, but that visual information relative to significant landmarks is largely preserved. If this is true, then on a route learning task he ought to benefit from the availability of visual landmarks which should at least partially compensate for the loss of spatial information. In order to verify this hypothesis, the patient underwent a maze learning test, which contrasted a condition in which route learning was exclusively based on the encoding of spatial cues and one in which route learning was at least partially supported by the availability of visual cues.

\section{Test}

The maze learning task involves discovering and learning a 12 block route through a $7 \times 7$ array of blocks, similar in form to that described by De Renzi et al. ${ }^{2}$ When an error is made, the patient is required to try again from the starting block. The task continues until the route is reproduced without error on three consecutive trials. To assess long term retention of the learned route, the patient is also asked to reproduce the route following a 15 minute delay after completion of the learning trials. Three different mazes are presented, differing in the number of visual cues (drawings from Snodgrass and Vanderwart's $s^{t^{50}}$ ) reported over the blocks. The first maze has no visual cues (without landmarks condition), the second has 23 visual cues randomly located on the matrix (few landmarks condition), and the third maze has visual cues located over each of the 49 blocks (full landmark condition).

\section{Results and comment}

The performance of the patient and the controls on the maze learning task are summarised in table 5 . When performance was evaluated as the number of trials needed to reach the learning criterion, the patient's scores varied strikingly as a function of visual cue availability. He was not able to learn the route in the "without landmarks" condition even after 43 trials; in contrast, the number of trials he needed to learn both the "few landmarks" and the "full landmark" routes was in the range of the normal controls. These results confirmed the prediction of the present experiment-that is, that the presence of visual-perceptual information greatly improves our patient's ability to learn a route. However, his performance on the delayed test was below normal limits in all experimental conditions, probably because effective long term retention of a learnt route requires the integration of both visual and spatial information. Confirming the non-selective nature of the pathological controls' long term memory impairment, their scores were below the normal limits in all test conditions.

\section{Experiment 4: topographical retrograde memory}

The aim of the following experiments was to investigate the patient's self report that his topographical troubles were limited to the learning of routes in previously unfamiliar environments. For this purpose, we explored his geographical knowledge and memory for visual landmarks and routes acquired before the onset of the amnesic syndrome.

\section{Tests}

In each of the 15 trials of the famous buildings recognition test, ${ }^{48}$ the pictures of one famous building (for example, the Eiffel Tower, the Santa Maria degli Angeli Church in Florence, and so on) and of three non-famous buildings are presented simultaneously. Subjects are required to provide three responses: (a) familiarity judgement (pointing to the famous building); (b) verbally reporting the town in which the building is located; and (c) its name.

The geographical knowledge test assesses memory for position over a map of 10 Italian cities and 10 European cities. In each trial, the subject is presented with a blank map and asked to indicate the exact location of a verbally presented town.

In the route description test, ${ }^{48}$ the subject is given the names of two well known places in Rome and is requested to verbally describe the shortest route linking the two places, mentioning street names, change of direction, notable monuments (for more detailed description, see Carlesimo et al ${ }^{48}$ ).

\section{Results and comment}

These results are shown in table 6. The patient scored within the normal range on all tests, supporting his self report that the topographical deficit was confined to the acquisition of new information. The pathological control with selective hippocampal damage also performed in the normal range on all tests of experiment 4 . The poor performance achieved by the 
Table 6 Performance scores of the patient and of the healthy and pathological controls on tests in experiment 4

\begin{tabular}{|c|c|c|c|c|}
\hline & \multirow[b]{2}{*}{ Patient } & \multirow[b]{2}{*}{$\begin{array}{l}\text { Normal controls } \\
\text { (range) }\end{array}$} & \multicolumn{2}{|c|}{ Pathological controls } \\
\hline & & & $\begin{array}{l}\text { Patient with } \\
\text { hippocampal } \\
\text { atrophy }\end{array}$ & $\begin{array}{l}\text { Patient with } \\
\text { cortical atrophy }\end{array}$ \\
\hline \multicolumn{5}{|l|}{ Famous buildings recognition } \\
\hline Familiarity & 15 & $13-15$ & 14 & $8^{*}$ \\
\hline Town & 15 & $13-15$ & 15 & $3^{*}$ \\
\hline Name & 14 & $12-15$ & 15 & $5^{*}$ \\
\hline \multicolumn{5}{|l|}{ Geographical knowledge } \\
\hline Italy & $11.8 \mathrm{~mm}$ & $9.1-18.5 \mathrm{~mm}$ & $10.3 \mathrm{~mm}$ & $26.7^{*} \mathrm{~mm}$ \\
\hline Europe & $13.8 \mathrm{~mm}$ & $5.9-18.1 \mathrm{~mm}$ & $9.7 \mathrm{~mm}$ & $36.3^{*} \mathrm{~mm}$ \\
\hline Route verbal description & 12.2 & $3.0-13.6$ & 9.8 & $2.3^{*}$ \\
\hline
\end{tabular}

patient with Alzheimer's disease showed that his memory deficit also affected the retrograde domain.

\section{DISCUSSION}

We have described the case of a patient suffering from a particularly severe deficit of topographical orientation in the context of a mild global amnesic syndrome. Qualitatively, his topographical disorientation was characterised by being restricted to the anterograde domain, and by being subtended by a particularly severe impairment in the learning of spatial information.

As described above, in the few reported cases of topographical disorientation confined to unknown environments in the absence of a persistent retrograde deficit, the memory disorder mainly regarded the visual-perceptual domain with a relative (or absolute) sparing of the memory for visual-spatial information. ${ }^{16-18} 2021$ In contrast to these cases, our patient's crucial neuropsychological defect was an impairment in learning the spatial relations between visually processed objects. Based on the patient's self report that after he visited new environment or ran through a new route, he was able to recognise the previously seen buildings and places, but that these visual landmarks did not seem to convey any directional information when he tried to run through the same route again or to find some place in the area, we assumed that a spatial memory disorder was the source of his topographical disorientation. Experiments 1 to 3 confirmed the dissociation in the patient's anterograde memory deficit between only mildly impaired ability to learn verbal and visual information and almost complete lack of ability to remember spatial information. In view of this normal performance on visual-spatial working memory and mental imagery tasks, his deficit should not be attributed to difficulty in forming and manipulating spatial representations but rather in consolidating these representations in the long term memory store. The pattern of selective impairment of spatial anterograde memory was specific to this patient. In the two pathological controls-whose brain damage partially overlapped that of the patient ( the first with selective hippocampal atrophy caused by hypoxia, the second with diffuse degenerative cortical damage)performance on the same experimental tasks was homogeneously impaired, affecting anterograde memory for verbal, visual, and spatial data to the same degree.

In the previously reported cases of anterograde topographical disorientation, the lesion site was generally found in the inferior ventral cortex of the right hemisphere, most regularly involving the parahippocampal gyrus ${ }^{161720}$ (for review, see Aguirre and $\mathrm{D}^{\prime}$ Esposito $^{6}$ ). Instead, in this patient the crucial neuropathological damage was a severe reduction of hippocampal volume without predominance of side, associated with neocortical atrophic changes that were more evident in the fronto-parietal dorsal regions. Indeed, within the resolution limits of $1 \mathrm{~mm}^{3}$, the MRI investigation did not reveal any other focal lesion in the cerebral parenchyma, particularly in the occipito-temporal ventro-mesial regions.

As previously observed, although the role of the parahippocampal cortex in topographical orientation is well established (based on neuropsychological evidence and functional neuroimaging data), the issue of the relation between the hippocampus and topographical orientation is controversial. In a recent study of a large group of patients with stable and focal brain lesions ( 127 patients), Barrash and colleagues ${ }^{51}$ found a route learning impairment in 10 of 13 subjects with hippocampal lesions and in 12 of 14 patients with lesions involving the parahippocampus. The authors assumed that the hippocampal and parahippocampal cortices have different specificity in topographical memory. The parahippocampus is critically involved in combining visual information about the form of scenes and landmarks with spatial information about their locations in a unified topographical representation, whereas the hippocampus is crucial for consolidating this representation.

In our patient, the finding of topographical disorientation confined to the learning of new routes in unfamiliar environments is consistent with Barrash et al's claim ${ }^{51}$ of involvement of the hippocampal formation in consolidating new topographical representations, and with the role more generally assigned to the hippocampus in memory functioning. According to a great deal of experimental evidence in both humans and animals, the critical role of the hippocampal circuitry is generally held to be transitory storage of recently acquired information and the successive long term consolidation of memory traces in the associative neocortex. ${ }^{52-54}$ Actually, a possible role of the hippocampus as a definitive repository of topographical representations has been hypothesised by some investigators, ${ }^{55}$ but neuropsychological data in this regard are controversial. ${ }^{56}$ The high performance level achieved by our patient on retrograde topographical memory tests, in spite of his very marked bilateral hippocampal atrophy (in this case, consistent with the performance of the neurological control with hippocampal atrophy) is clearly at variance with this hypothesis.

It is more difficult to understand why the patient's anterograde memory deficit affects spatial rather than verbal and visual information in such a disproportionate way. There are two possible interpretations of this finding. The first relates to the supposed prevalent role played by the hippocampus in the memory for spatial rather than non-spatial material. Based on the evidence of a prevalent role of the hippocampus in spatial learning in rodents, ${ }^{26} 27$ some investigators have advanced the hypothesis that the hippocampus is also mainly involved in 
consolidating spatial information in humans, with a less crucial role in consolidating other kinds of information (for example, verbal or visual). However, results of studies experimentally testing this hypothesis in groups of patients with anterograde amnesia are, at the very least, contradictory. Some studies report relatively worse performance on spatial than on non-spatial memory tests in these patients ${ }^{57}{ }^{58}$ while others report a homogeneous impairment across different categories of information. ${ }^{59}$ On the other hand, the dissociation between substantially spared verbal and visual memory and severely disturbed spatial memory observed in our patient is undoubtedly too strong to be assimilated in the relative prevalence of the spatial over non-spatial deficit reported in some of the previous group studies.

Rather, this case seems more in line with previously reported cases of patients with anterograde amnesic syndromes that selectively involved or spared some types of information. The most obvious dissociation in this regard is that between verbal and visual-spatial memory impairment. ${ }^{60} 61$ More recently, a far less obvious dissociation was described between impaired ability to learn different classes of visual objects. For example, Tippett et al reported the case of a patient with right temporal lobectomy who was impaired in the learning of previously unknown faces but learned other kinds of visual and non-visual information at a normal rate. ${ }^{62}$ Recently, a double neuropsychological dissociation in the anterograde memory impairment for two different classes of visual objects, namely faces and topographical scenes, was reported. In particular, Cipolotti and coworkers ${ }^{63}{ }^{64}$ reported the cases of two patients with a severe impairment in learning unfamiliar faces but a completely spared ability to recognise recently seen topographical material. Conversely, the patient described by Carlesimo et al had a severe deficit in learning verbal, spatial, and visual-topographical material but learned new faces at a normal rate. ${ }^{48}$ In the context of these reports, our patient represents the previously unreported case of a person with an anterograde memory impairment confined to (or at least disproportionately more severe for) spatial information, with a relative sparing of the ability to learn verbal and visual-object material.

Taken together, the material specific memory impairment found in these patients argues for a high degree of domain specificity in the neural systems involved in learning new information. It is not a novelty that distinct cortical regions are specifically involved in the processing of verbal, visual, and spatial data and —in the visual domain — of different classes of objects. What emerges from the report of patients with anterograde memory deficits restricted to a single class of visual objects is that this domain specificity is not confined to the cortical areas that are the definitive repository of long term memory traces, but also involves the neural circuits implicated in the storage of new memory representations. In particular, in the hippocampus and in the pathways connecting the hippocampi and the neocortex, the neural circuits involved in the storage of material-specific information could maintain a reciprocal segregation, so that focal damage in these circuits may differentially affect the learning of different kinds of information.

It is interesting to note that the neocortical atrophic changes in the patient's brain most markedly affected the parieto-frontal dorsal regions which have a generally accepted role in the processing of spatial information. ${ }^{12} 136566$ Although he did not display any damage in spatial processing (his performance on perceptual, short term memory and visual imagery tasks involving spatial data was largely preserved), we suggest that his specific anterograde memory deficit for spatial data actually resulted from the interaction between atrophic changes in the hippocampi and in the dorsal parietal regions, ultimately affecting the neural circuitry involved in the acquisition and consolidation of new spatial information.

\section{Authors' affiliations}

P Turriziani, G A Carlesimo, R Perri, F Tomaiuolo, C Caltagirone,

IRCCS Fondazione Santa Lucia, Rome, Italy

G A Carlesimo, Caltagirone, Clinica Neurologica, Universitò Tor Vergata, Rome

Competing interests: none declared

\section{REFERENCES}

1 Bottini G, Cappa S, Geminiani G, et al. Topographic disorientation: a case report. Neuropsychologia 1990;28:309-12.

2 De Renzi E, Faglioni P, Villa P. Topographical amnesia. J Neurol Neurosurg Psychiatry 1977;40:498-505.

3 Landis T, Cummings JL, Benson DF, et al. Loss of topographic familiarity. An environmental agnosia. Arch Neurol 1986;43:132-6.

4 Paterson A, Zangwill OL. A case of topographical disorientation associated with a unilateral cerebral lesion. Brain 1945;68:188-212.

5 Whiteley AM, Warrington EK. Selective impairment of topographical memory: a single case study. J Neurol Neurosurg Psychiatry 1978;41:575-8

6 Aguirre GK, D'Esposito M. Topographical disorientation: a synthesis and taxonomy. Brain 1999;122:1613-28.

7 Hécaen $\mathrm{H}$, Tzortzis $\mathrm{C}$, Rondot $\mathrm{P}$. Loss of topographic memory with learning deficits. Cortex 1980;16:525-42.

8 Pallis CA. Impaired identification of faces and places with agnosia for colours. J Neurol Neurosurg Psychiatry 1955;18:218-24.

9 Aguirre GK, Dettre JA, Alsop DC, et al. The parahippocampus subserves topographical learning in man. Cereb Cortex 1996;6:823-9.

10 Maguire EA, Burgess N, Donnett JG, et al. Knowing where and getting there: a human navigation network. Science 1998;280:921-4.

11 Maguire EA, Frith CD, Burgess N, et al. Knowing where things are: parahippocampal involvement in encoding object locations in virtual large-scale space. J Cogn Neurosci 1998;10:61-76.

12 Levine DN, Warach J, Farah M. The two visual systems in menta imagery: dissociation of "what" and "where" in imagery disorders due to bilateral posterior cerebral lesions. Neurology 1985;35:1010-18.

13 Stark M, Coslett HB, Saffran EM. Impairment of an egocentric map of locations: implications for perception and action. Cogn Neuropsychol 1996; 13:481-523.

14 Takahashi N, Kawamura M, Shiota J, et al. Pure topographic disorientation due to right retrosplenial lesion. Neurology 1997;49:464-9.

15 Cammalleri R, Gangitano M, D'Amelio $M$, et al. Transient topographical amnesia and cingulate cortex damage: a case report. Neuropsychologia 1996;34:321-6.

16 Epstein R, DeYoe EA, Press DZ, et al. Neuropsychological evidence for a topographical learning mechanism in parahippocampal cortex. Cogn Neuropsychol 2001;18:481-508.

17 Habib M, Sirigu A. Pure topographical disorientation: a definition and anatomical basis. Cortex 1987;23:73-85

18 Hublet C, Demeurisse G. Pure topographical disorientation due to a deep-seated lesion with cortical remote effects. Cortex 1992;28:123-8.

19 Pai MC. Topographical disorientation: two cases. J Formos Med Assoc 1997;96:660-3.

20 Ross ED. Sensory-specific and fractional disorders of recent memory in man. I. Isolated loss of visual recent memory. Arch Neurol 1980:37:193-200.

21 Scotti G. [La perdita della memoria topografica: descrizione di un caso] (The loss of topographical memory: a case description). Sistema Nervoso 1968;58: $11-28$.

22 Landis T, Cummings JL, Benson DF, Palmer EP. Loss of topographic familiarity. An environmental agnosia. Arch Neurol 1986;43:132-6.

23 McCarty RA, Evans JJ, Hodges IR. Topographical amnesia: spatial memory disorder, perceptual dysfunction, or category specific semantic memory impairment? J Neurol Neurosurg Psychiatry 1996;60:318-25.

24 O'Keefe J, Dostrovsky J. The hippocampus as spatial map: preliminary evidence from unit activity in activity in the freely-moving rat. Brain Res 1971;34:171-5.

25 Rolls ET, MiyashitaY, Cahusac PM, et al. Hippocampal neurons in the monkey with activity related to the place in which a stimulus is shown. $J$ Neurosci 1989:9:1835-45.

26 Barnes CA. Spatial learning and memory process: the search for their neurobiological mechanisms in the rat. Trends Neurosci 1988;11:163-9.

27 Morris RGM, Garrud P, Rawlins JNP, et al. Place navigation impaired in rats with hippocampal lesions. Nature 1982;297:681-3.

28 De Renzi E. Disorders of space explanation and cognition. Chichester John Wiley, 1982.

29 Maguire EA, Burke T, Phillips J, et al. Topographical disorientation following unilateral temporal lobe lesions in humans. Neuropsychologia 1996:34:993-1001.

30 Aguirre GK, Zarahn E, D'Esposito M. Neural components of topographical representation. Proc Natl Acad Sci USA 1998;95:839-46.

31 Gron G, Wunderlich AP, Spitzer M, et al. Brain navigation during human navigation: gender-different neural networks as a substrate of performance. Nat Neurosci 2000;3:404-8. 
32 Maguire EA, Frackowiak RSJ, Frith CD. Learning to find your way: a role for the human hippocampal formation. Proc $R$ Soc Lond (Biol) 1996;263: 1745-50

33 Maguire EA, Frackowiak RSJ, Frith CD. Recalling routes around London: activation of the right hippocampus in taxi drivers. J Neurosci 1997:17:7103-10.

34 Mellet E, Bricogne S, Tzourio-Mazoyer N, et al. Neural correlates of topographic mental exploration: the impact of route versus survey perspective learning. Neuroimage 2000;12:588-600.

35 Aguirre GK, D'Esposito M. Environmental knowledge is subserved by separable dorsal/ventral neural areas. J Neurosci 1997;17:2512-18.

36 Wechsler D. Wechler adult intelligence scale. New York: Psychological Corporation, 1955.

37 Raven JC. Progressive matrices (1947), sets A, Ab, B: board and book forms. London: Lewis, 1949.

38 Carlesimo GA, Caltagirone C, Gainotti G, et al. The mental deterioration battery: normative data, diagnostic reliability and qualitative analyses of cognitive impairment. Eur Neurol 1996;36:378-84.

39 Nelson HE. A modified card sorting test sensitive to frontal lobe defects. Cortex 1976;12:313-24

40 Warrington EK, James M. The visual object and space perception battery. Bury St Edmunds: Thames Valley Test Company, 1991.

41 Benton AL, Van Allen MW. Impairment in facial recognition in patients with cerebral disease. Cortex 1968:4:344-58.

42 Spinnler $\mathbf{H}$, Tognoni $\mathrm{G}$. Standardizzazione e taratura italiana di test neuropsicologici. Ital J Neurol Sci 1987 (suppl 8)

43 Benton AL, Varney NR, Hamsher K. Visuospatial judgment. A clinica test. Arch Neurol 1978:35:364-67.

44 Wechsler D. A standardized memory scale for clinical use. J Psychol 1945; 19:87-95.

45 Orsini A, Grossi D, Capitani E, et al. Verbal and spatial immediate memory span: normative data from 1355 adults and 1112 children. Ital J Neurol Sci 1987;8:539-48.

46 Brooks AL. The suppression of visualisation by reading. Q J Exp Psychol 1967;19:289-99.

47 Carlesimo GA, Buccione I, Fadda L, et al. [Standardizzazione di due test di memoria per uso clinico: breve racconto e Figura di Rey.] Nuova Rivista Neurologia 2002;12:1-13.

48 Carlesimo GA, Fadda L, Turriziani $P$, et al. Selective sparing of face learning in a global amnesic patient. J Neurol Neurosurg Psychiatry $2001 ; 71: 340-6$

49 Maguire EA, Frith CD, Cipolotti L. Distinct neural systems for the encoding and recognition of topography and faces. Neuroimage $2001 ; 13: 743-50$.
50 Snodgrass JG, Vanderwart M. A standardized set of 260 pictures: norms for name agreement, image agreement, familiarity, and visua complexity. J Exp Psychol Hum Learn Mem 1980;6:174-215.

51 Barrash J, Damasio A, Adolphs R, et al. The neuroanatomical correlates of route learning impairment. Neuropsychologia 2000;38:820-36.

52 Kapur N. Syndromes of retrograde amnesia: a conceptual and empirical synthesis. Psychol Bull 1999;125:800-25

53 Squire LR. Memory and the hippocampus: a synthesis from findings with rats, monkeys, and humans. Psychol Rev 1992;99:195-231.

54 Zola-Morgan S, Squire LR. The primate hippocampal formation: evidence for a time-limited role in memory storage. Science 1990;250:288-90.

55 Maguire EA, Gadian DG, Johnsrude JS, et al. Navigation-related structural change in the hippocampi of taxi drivers. Proc Natl Acad Sci USA 2000;97:4398-403.

56 Teng E, Squire LR. Memory for places learned long ago is intact after hippocampal damage. Nature 1999;400:675-7.

57 Chalfonte BL, Verfaellie M, Johnson MK, et al. Spatial location memory in amnesia: binding item and location information under incidental and intentional encoding conditions. Memory 1996:4;591-614.

58 Mayes AR, Meudell PR., MacDonald C. Disproportionate intentional spatial-memory impairments in amnesia. Neuropsychologia 1991;29:771-84.

59 Cave CB, Squire LR. Equivalent impairment of spatial and nonspatial memory following damage to the human hippocampus. Hippocampus $1991 ; 1: 329-40$.

60 Hanley JR, Pearson N, Young AW. Impaired memory for new visual forms. Brain 1990;113:1131-48.

61 Milner B. Disorders of learning and memory after temporal lobe lesions in man. Clin Neurosurg 1972;19:421-46.

62 Tippett LJ, Miller LA, Farah M. Prosopoamnesia: a selective impairment in face learning. Cogn Neuropsychol 2000;17:241-55.

63 Cipolotti L, Robinson G, Blair J, et al. Fractionation of visual memory: evidence from a case with multiple neurodevelopmental impairments. Neuropsychologia 1999;37:455-65.

64 Maguire EA, Cipolotti L. Selective sparing of topographical memory. $J$ Neurol Neurosurg Psychiatry 1998;65:903-9.

65 Ungerleider LG, Mishkin M. Two cortical visual systems. In: Ingle DJ, Goodale MA, Mansfield RJV, eds. The analysis of visual behavior. Cambridge, MA: MIT Press, 1982:549-86.

66 Carlesimo GA, Perri R, Turriziani $P$, et al. Remembering what but not where: independence of spatial and visual working memory in the human brain. Cortex 2001;37:519-34.

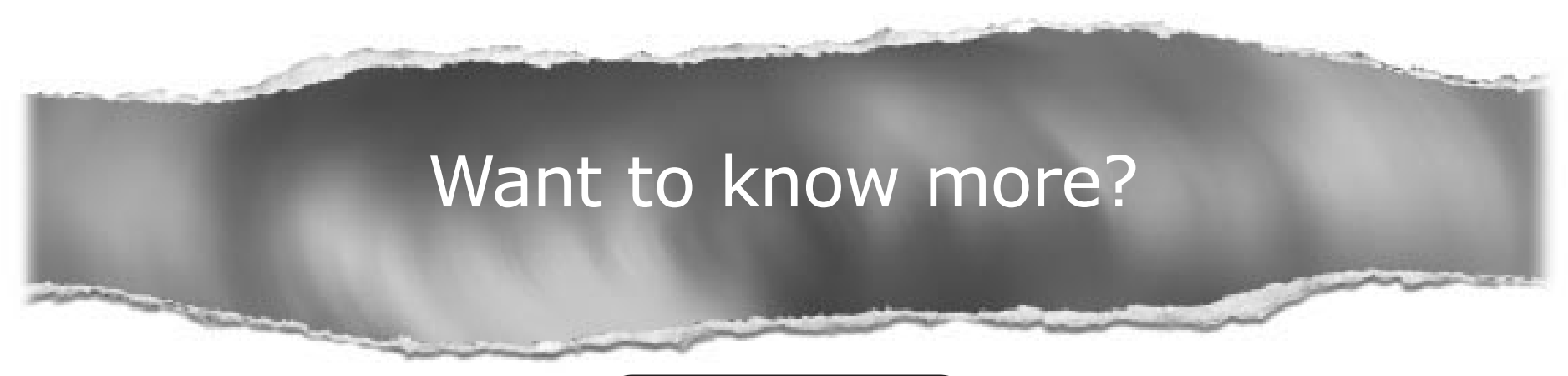

\section{Data supplements}

Limited space in printed journals means that interesting data and other material are often edited out of articles; however, limitless cyberspace means that we can include this information online.

Look out for additional tables, references, illustrations.

www.jnnp.com 


\section{CORRESPONDENCE}

\section{Measuring carotid stenosis}

Comparing a new test with a standard involves measuring disagreement. In the case of measuring carotid artery stenosis, some of the disagreement between different tests is because of inherent differences in how the stenosis is demonstrated (test characteristics). This is what we are most interested in when assessing a new technology. However, some of the disagreement simply reflects variability in how we physically make the measurement with the standard technique. Choosing the point of maximum stenosis, choosing the point in the common carotid artery for use as a denominator, measuring from an eyepiece, or measuring from calipers all introduce variation when measuring carotid stenosis. The resulting observer variability in reporting contributes to disagreement between methods but to some extent is independent of the method used to generate the angiogram in the first place.

In the medical literature, disagreement between methods is often attributed entirely to test characteristics, with little appreciation of the role of observer variability in reporting. When one method is compared with anothe and disagreements emerge, it is not readily apparent how much of the disagreement is caused by the method used and how much by the process of measurement, unless observe variability data are also presented. In the recent paper from Patel et al, interobserver variability data are presented but their significance in relation to overall agreement does not appear to have been appreciated.

Using the data from Patel et al (tables 2 and 4) for symptomatic carotid arteries, it is noted that when 34 carotid digital subtraction angiograms (DSA) are measured by one radiologist, there was disagreement in seven cases when the same films were reported by a second radiologist. Therefore if only DSA was used, seven patients would have had "inappropriate" surgery according to which radiologist read the angiogram. This is no surprising, and such disagreement is a consistent finding in observer variability studies. $^{23}$ Observer variability in reporting DSA therefore accounted for approximately $20 \%$ of disagreement in this particular series of angiograms. This sets a limit on the maximum agreement that any alternative method can demonstrate when compared with DSA. It is clearly not reasonable to expect better agreement from another method than can be obtained by re-reporting the DSAs themselves. In Patel's table 2, when the same arteries are assessed by computed tomographic angiography (CTA) there was disagreement with DSA in seven cases, while with magnetic resonance angiography (MRA) and ultrasound there was disagreement in six and seven cases, respectively. The three alternatives thus disagree with DSA to the same extent as can be attributed to observer disagreement in reporting DSA. Put simply, the same number of missed or unnecessary operations would have occurred (roughly 20\% in this series) whatever method was used, including DSA alone. Observer variability is not confined to DSA, and the scatter plots from Patel et al (fig 2) would suggest-in keeping with other studies-that observer variability is greater for MRA and CTA than for DSA. ${ }^{1}$ It is surprising that this did not translate into more clinically important disagreements when MRA and CTA were compared with DSA. This is probably accounted for by the fact that in this study, for MRA and CTA, consensus views were taken for any disagreements greater than $10 \%$ between observers.

This highlights the important point that combining multiple observations made on the same data will reduce observer variability, and ultimately improve agreement with other methods. Partly for this reason, but also because to some extent the strengths and weaknesses of CTA, MRA, and duplex ultrasound are complementary, we would suggest that a combination of tests (we use the combination of ultrasound and MRA) should be used in preference to DSA.

What is clear from this study is that most of the disagreement between the different methods of measuring carotid stenosis can be attributed to observer variability in reporting rather than to the test characteristics of the individual methods themselves. The $10 \%$ of patients injured as a result of DSA in this study, and those who continue to be put at risk from catheter angiography in these circumstances, would be quite entitled to ask why they are exposed to a procedure which appears to offer no great advantage over safer alternatives. We suggest that more studies are not required, simply a more thorough understanding of presently available information.

G Young

Middlesbrough General Hospital, Ayresome Green Lane, Middlesbrough TS5 5AZ, UK

P Humphrey

The Walton Centre, NHS Trust, Liverpool, UK

Correspondence to: Dr G Young; gavin.young@stees.nhs.uk

\section{References}

1 Patel SG, Collie DA, Wardlaw JM, et al. Outcome, observer reliability, and patient preferences if CTA, MRA, or Doppler ultrasound were used, individually or together instead of digital subtraction angiography before carotid endarterectomy. J Neurol Neurosurg Psychiatry 2002;73:21-8.

2 Rothwell PM, Gibson RJ, Slattery J, et al. Prognostic value and reproducibility of measurements of carotid stenosis. A comparison of three methods on 1001 angiograms. European Carotid Surgery Trialists' Collaborative. Stroke 1994;25:2440-4

3 Young GR, Sandercock PA, Slattery J, et al Observer variation in the interpretation of intra-arterial angiograms and the risk of inappropriate decisions about carotid endarterectomy. I Neurol Neurosurg Psychiatry 1996;60:152-7.

\section{Author's reply}

Doctors Young and Humphrey highlight that differences between tests arise from several factors, some of which are inherent in the test and some of which arise from aspects attributable to observer variation. Some of the aspects to do with observer variation apply to interpretation of all tests and some are specific to certain tests. In our study we were endeavouring to quantify the effect on patient management if non-invasive tests were used instead of intra-arterial angiography to assess carotid stenosis. Our study has several limitations, including a relatively small sample size, and the fact that we were not able to get all scans read by all observers but rather had to get pairs of observers to concentrate on reading only CTA, or MRA, or DSA. A better design would have been to keep the same workers together in pairs but randomly assign the CTA, MRA, or DSA films to each pair. As it is, it is possible that some of the apparent difference between imaging modalities is specific to the pair of observers, not to the modality. However, imaging studies are difficult to fund and expensive to do, and the result and design of our study was a compromise involving all these factors.

We identified that the observer reliability of CT angiography or MR angiography was worse than that for digital subtraction angiography, as highlighted by Drs Young and Humphrey. Also in general there was more scatter between the observers for the reading of asymptomatic stenoses than for symptomatic stenoses (emphasising the importance of considering patient characteristics, not just the imaging technique). In the determination of the effect that this disagreement might have on patient management, we used nomograms derived from the European carotid surgery trial which were based on intra-arterial angiographic measurement of stenosis. We therefore had to use the comparison of non-invasive test reading with DSA rather than being able to use the individual observers readings of non-invasive tests. Thus as Drs Young and Humphrey point out, the actual effect of using non-invasive tests maybe worse than we have estimated.

Finally, Drs Young and Humphrey suggest that more studies are not required but we are not entirely sure that that is completely true. Non-invasive imaging tests are continually undergoing modifications, many of which may be improvements in accuracy or practicality, but this cannot be assumed to be the case. Much of this tinkering with technology is driven by the manufacturer's desire to encourage purchase of new machines. Improvements have also occurred in intraarterial angiography with smaller and more manoeuvrable catheters and greater awareness of the risks, which may have helped to reduce the risk of angiography. Our "snap shot" of CTA, MRA, and ultrasound is already out of date because contrast MRA is now increasingly used. While we would hope that non-invasive tests (probably in combination rather than alone) would eventually replace intra-arterial angiography in the majority of patients being considered for carotid intervention, we feel it likely that there will always be a need for some intra-arterial angiography in specific cases, or depending on local resources. In any case DSA did not appear less popular than MRA among the patients in our study. There is certainly room for much more in depth examination of existing data but we shouldn't close the door on the need for further studies. 


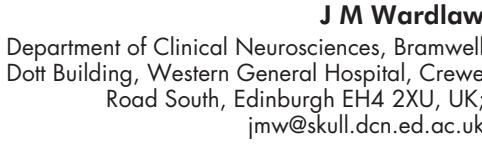

\section{Cerebral metastasis after primary renal cell carcinoma}

The article by Roser et al, ${ }^{1}$ in which it was shown that the treatment of intracranial metastases originating from renal cell carcinoma can on occasion be successful, was most interesting.

We have followed the clinical course of a patient with a renal cell carcinoma with a low mitotic index since 1989. In this patient the course was distinctly more malignant but the disease has also been successfully treated to date. In the last 13 years, this patient has had four metastases surgically removed and a further nine treated with stereotactically guided percutaneous single dose convergent beam irradiation therapy (stereotactic modified linear accelerator, 6-15 MV photons, 18-20 Gy prescribed to the $80 \%$ isodose). Apart from slight mnemonic deficits, the patient is in good health

The following factors which affect the prognosis $^{2-4}$ were all met by our patient

- The interval between the diagnosis of renal cell carcinoma and the first detected brain metastasis exceeds 17 months (our patient, 18 months; the patient described by Roser et al, ${ }^{1} 36$ months);

- Age below 60 years at the time of initial diagnosis;

- Primary tumour of the left kidney, initial nephrectomy;

- Diameter of primary metastasis $<2 \mathrm{~cm}$;

- Not more than one brain metastasis at the time of initial treatment;

- Solely intracranial metastases;

- Karnofsky > 70\%;

- No systemic symptoms such as fever or weight loss at the time of diagnosis;

- Blood sedimentation rate under $50 \mathrm{~mm} / \mathrm{h}$ at diagnosis of renal cell carcinoma.

Patients in whom prognostic factors predict a good outcome should be treated with intent to cure.

S Heckl

Department of Neuroradiology, University of Heidelberg Medical School, Kopfklinik, Im Nevenheimer Feld 400, 69120 Heidelberg,

Germany

K Braun, J Debus

Department of Radiation Oncology, German Cancer Research Centre, Heidelberg

S Kunze

Department of Neurosurgery, University of

Heidelberg

Correspondence to: Dr med Stefan Heckl s.heckl@dkfz-heidelberg.de

\section{References}

1 Roser F, Rosahl SK, Samii M. Single cerebral metastasis 3 and 19 years after primary renal cell carcinoma: case report and review of the literature. J Neurol Neurosurg Psychiatry 2002;72:257-8.

2 Decker DA, Decker VL, Herskovic A, et al. Brain metastases in patients with renal cell carcinoma, prognosis and treatment. J Clin Oncol 1984;2: 169-73.
3 Wronski MD, Maor MH, Davis BJ, et al. External radiation of brain metastases from renal carcinoma: a retrospective study of 119 patients from the M D Anderson Cancer Center. Int J Radiat Oncol Biol Phys 1997:37:753-9.

4 Culine S, Bekradda M, Kramar A, et al. Prognostic factors for survival in patients with brain metastases from renal cell carcinoma. Cancer 1998;83:2548-53.

\section{BOOK REVIEWS}

\section{Seizures, medical causes and management}

Edited by Norman Delanty (Pp 352 US\$1 25.00). Published by the Humana Press New Jersey, 2002. ISBN 0-89603-827-0

This book is unusual among books about seizures because it focuses on acute symptomatic ("situation-related") seizures, rather than "epilepsy" (although there is inevitably some overlap between the two). It provides definitions and describes the epidemiology and pathophysiology of acute symptomatic seizures in the initial section, which is followed by chapters detailing the specific circumstances in which such seizures are likely to occur, often (although not invariably) including points of management specific to the situation. Subjects covered include seizures occurring in the context of multisystem disease, infection, hypoxic-ischaemic cardiopulmonary conditions, endocrine disorders, cancer and other conditions. Situation-related seizures occurring as a result of drugs or alcohol misuse are also addressed, as are those occurring in the intensive care situation, and the difficult, but important, differentiation of seizures from syncope. The book ends with a very practical chapter entitled "Anticonvulsants in acute medical illness", in which the considerations affecting the choice of antiepileptic drug in the acute situation are reviewed.

Although situation-related seizures are usually discussed in books about epilepsy, they do appear to constitute a distinct group in a number of respects including prognosis. To a certain extent the topics discussed in the book form a rather disparate group linked only by their tendency to cause such seizures as a reflection of central nervous system disturbance. Nevertheless, they are all conditions likely to be encountered at various times by general physicians, neurologists, and those working in the accident and emergency department, and this book, which is both readable and comprehensively referenced, will be of interest to all these groups.

Yvonne Hart

\section{Subcortical stroke, 2nd edition}

Edited by Geoffrey Donnan, Bo Norrving, John Bamford, and Julien Bogousslavsky (Pp 450, £79.50). Published by Oxford University Press, New York, 2002. ISBN 0-19-263-157-8

This book is a must read for clinicians and researchers with an interest in stroke. The four editors are all specialist stroke clinicians who have been thinking about and leading research in subcortical stroke for many years, and they have put together a well constructed and comprehensive multiauthor work. This second edition is longer and more extensive than the first, reflecting the considerable and rapid advances in our understanding of subcortical strokes in recent years, and in particular the increasingly sophisticated neuroimaging techniques. Given the large number of contributors, consistency of style and approach is limited, but this is more than made up for by the breadth of expertise and opinion.

There are some particular strengths. These include the editors' short chapter providing a summary classification of subcortical infarcts, which is best appreciated if read both before and after tackling most of the other chapters. The excellent chapter on pathology of lacunar infarction is a welcome addition to this edition, while the chapters discussing risk factors and prognosis provide very useful commentaries and summary tables of all the relevant studies. The discussion around the usefulness (or not) of clinical diagnosis of lacunar syndromes, carefully updated with the information from recent clinicoradiological studies, is both thoughtful and logical, with plenty of clinical and epidemiological common sense.

In common with all recently published medical textbooks, this one is already a little out of date. This is most noticeable for the chapter on therapy, where recent advances (for example, new evidence on blood pressure lowering from the PROGRESS trial and on cholesterol reduction with a statin from the Heart Protection Study) are likely to have most impact on clinical practice. If the editors have the energy to produce a third edition, there is (as always) some room for improvement. The series of chapters on infarcts in specific subcortical territories would be enhanced by some figures illustrating the vascular anatomy that is discussed in the text. In addition, the quality of the discussion of study methodology varies considerably between chapters, and some would benefit from a more systematic and accurate approach to statistical and epidemiological concepts.

Cathie Sudlow

\section{Medical risks in epilepsy}

Edited by Svein I Johannessen, Torbjörn Tomson, Matti Sillanpää, and Birthe Pedersen (Pp 140, £29). Published by Wrightson Biomedical Publishing Ltd, Hampshire, 2002. ISBN 1- 871816-46-7

This is a very useful, reasonably comprehensive yet succinct multiauthor small book on medical risks associated with epilepsy. Areas covered include methodological aspects; accidents and risks in everyday life; traffic accidents; driving regulations; mortality, including SUDEP; psychiatric comorbidity and suicide; fatal adverse drug reactions reporting data (which are rather difficult to interpret); seizure-warning systems and risk prevention; as well as insurance related issues. It also highlights many areas where further research is required. The book generally provides an overview of the more recent research and publications in this area and includes some regulatory issues. Inevitably it has a Nordic emphasis; it includes very useful advice on precautionary measures to minimise risk of injury for people with uncontrolled epilepsy, including safer sauna. Some chapters, by necessity, serve purely as a compilation of available incomplete data. Others are written by key researchers directly involved in the area addressed and provide a very balanced review of current knowledge. On psychiatric comorbidity, while agreeing that "the positive 
effects of drug therapy on cognitive and affective functioning because of the reduction in seizure activity are usually far greater than the negative effects", more information would have been welcome in an otherwise very well balanced chapter. The book would well serve those for whom it is intended, namely epileptologists, neurologists, paediatric neurologists, psychiatrists, and other professionals who deal with patients with epilepsy. The editors rightly stress the "official line" that the majority of patients with epilepsy can achieve good control, with low associated risks.

Lina Nashef

\section{Greenfield's neuropathology, 7th edition}

Edited by David I Graham and Peter L Lantos. (2 Vol set (HB), Vol 1 ppl 190, Vol 2 ppl 140 $£ 395)$. Published by Arnold, London, 2002. ISBN 0-340-74231-3. CD rom (£145) ISBN 0-340-76-221-7.

What can one say. The latest (7th) edition of Greenfield's Neuropathology has hit the bookshops, and indeed what a resounding thud it makes! The present edition is bigger than ever, again running into two volumes, but now totalling a staggering 2330 pages and costing an equally staggering $£ 395$. It comes equipped with a handy $C D$ version of the illustrations, a mere snip at $£ 145$.

The 7th edition has undergone considerable changes in content, since the last edition five years ago, reflecting the ever expanding increase in knowledge of diseases of the nervous system and muscle that has come from the exponential growth in neuroscience research over the past decade. Areas of cellular and molecular neurobiology, and the contributions that genetics and neuroimaging have made towards improving our understanding of the causes of disease and our clinical investigative and diagnostic skills, are more strongly featured. Hence, while greater emphasis has been placed on the basic science of disease, the classic descriptive morphology for which Greenfield's is renown is well maintained. There are new chapters on "Metabolic and neurodegenerative diseases of childhood" and "Peroxisomal and mitochondrial diseases". The chapter on "Pathology of schizophrenia" has been shrewdly expanded to cover "The pathology of psychiatric disorders". Other chapters have been retained as such, but many have been rewritten with new authors reflecting the pre-eminence of each within their particular subspecialty. There is increased reliance on colour illustrations, line diagrams and tables to illuminate the text and these are of excellent quality throughout. As to be expected, all chapters are written authoritatively with clarity and style, comprehensively illustrated, and lavishly referenced. Judging by the content of the chapters on ageing and dementia, prion disease, and movement disorders, it is my guess that if anything is not included in each chapter, it's probably not worth including anyway. The accompanying $\mathrm{CD}$ rom is user friendly, and the images are downloadable - $\mathrm{a}$ boon to those wishing to produce a ready made lecture or presentation of distinction. The book is a must for practicing and trainee pathologists, but is equally compelling for workers in other clinical neuroscience disciplines and basic researchers interested in the roots of the dysfunctional nervous system. Possession of the 7th edition is guaranteed lasting quality and full value, but before lashing out make sure both your arms and shelving are strong enough to accommodate its presence.

David MA Mann

\section{Smell and taste complaints}

Edited by Christopher H Hawkes (Pp 176, £16.99). Published by ButterworthHeinemann, Woburn, 2002. ISBN 0-75067287-0.

Despite the fact that problems with tasting and smelling are common in the general population, few physicians have the knowledge and training to authoritatively deal with them. Christopher Hawke's Smell and Taste Complaints provides a straightforward guide to the understanding and management of chemosensory disturbances, reflecting the first clinically oriented book of its kind since Ellis Douek's The Sense of Smell and its Abnormalities (Edinburgh: Churchill Livingstone, 1974). This 180 page pocket sized book provides a cogent overview of the anatomy and physiology of the olfactory and gustatory systems, practical approaches towards their assessment, and suggestions for therapy and management. Importantly, it provides the practitioner with the names and addresses of specialised taste and smell clinics throughout the world, aiding the referral process. Although there is little new in this guide, and much of the material seems to have been derived from second hand sources, it presents the available information in a well organised and easy to read manner. Moreover, it addresses basic clinical issues rarely addressed in a single publication. Its major drawback is the lack of reference backing for many of its statements, some of which are questionable. I found, for example, some of the "facts" unfamiliar, and would have welcomed knowledge of their source. Bits of the material are dated (for example, the role of $\mathrm{IP}_{3}$ receptors in olfactory function, the nature of olfactory receptor cell regeneration) and several sections of the book seem lengthy, uncritical, and of little practical value. Thus, nearly seven pages are devoted to the topic of odour memory, a topic with inherent theoretical issues and problems that are not addressed by the author. However, the book is not intended to be a research book and, despite such shortcomings, it accomplishes its goal of educating the practitioner and providing him or her with a practical roadmap for clinical assessment and treatment. Indeed, the clinical information provided is comprehensive and well illustrated. This inexpensive book is a must for any physician who has the occasion to see patients with chemosensory disturbances or has even a casual interest in chemosensation, and should serve to elevate the level of appreciation of these senses within the medical community at large.

Richard L Doty

\section{CORRECTIONS}

The following errors occurred in the short report by Merlini L, Carbone I, Capanni C, et al. Familial isolated hyperCKaemia associated with a new mutation in the caveolin-3 (CAV-3) gene. J Neurol Neurosurg Psychiatry 2002;73:65-7. On page 66, left column, line 9, proline should replace leucine, line 12, protein should replace enzyme, and in table 1 , line 8 Del-TFT (63-65) should replace ?TFT (63-65).

We regret that an editing error occurred in the correspondence from Jaster JH, Dohan FC, and $\mathrm{O}^{\prime}$ Brien TF. Demyelination in the brain as a paraneoplastic disorder: candidates include some cases of seminoma and central nervous system lymphoma. J Neurol Neurosurg Psychiatry 2002;73;352. The description of a patient was altered, in the first line of the fourth paragraph the text should read "... patient who had a non-neurological malignancy, seminoma, and subsequently developed a paraneoplastic syndrome ...". 